\title{
Introduction
}

\section{La presse sous influence : la Russie et la presse francophone en Europe au siècle des Lumières ${ }^{1}$}

\author{
Vladislav Rjéoutski \\ Deutsches Historisches Institut Moskau \\ vladislav.rjeoutski@dhi-moskau.org
}

\begin{abstract}
Резюме
На протяжении всего XVIII в. пресса в Европе используется Россией, как и многими другими странами, в целях пропаганды. Этот тематический выпуск «Вивлиофики» рассматривает только франкоязычную прессу: в силу широчайшего распространения французского языка в Европе, число франкоязычных периодических изданий было очень значительным и эта пресса обладала большим влиянием на всем европейском континенте. По этой причине она использовалась наиболее интенсивно российскими властями. Во вступлении к этому выпуску тема политического влияния на прессу рассматривается в нескольких плоскостях. На ряде примеров, не претендующих на исчерпывающий характер, показано, какой образ России и ее государей чаще всего транслируется через франкоязычную прессу и в какой степени этот образ объясняется влиянием на нее. $B$ последней части анализируются связи между Россией и франкоязычной прессой с целью понять, какие группы агентов и посредников можно выделить и можно ли их соотнести с властными структурами или они преследуют собственные цели.
\end{abstract}

Mots clé

Russie; presse francophone européenne; propagande; agents littéraires ; intermédiaires culturels ; Académie des sciences ; diplomates

Aujourd'hui, les relations entre les médias et les pouvoirs sont discutées dans la société et par les médias eux-mêmes, et les collusions d'intérêt entre les deux sont régulièrement dénoncés, non seulement en Russie, mais partout dans le monde. Dans la société occidentale, il existe aujourd'hui un certain nombre de règles considérées par les journalistes et par la société civile comme une sorte de code de déontologie. Au XVIII siècle, il n'existait pas à proprement parler de déontologie d'un journaliste, même si la question était déjà débattue, y compris en Russie. Quand, en 1752, un article de Mikhaïl Lomonossov est sévèrement et peut-être injustement critiqué dans un journal de Leipzig ${ }^{2}$, le savant russe compose une «Réflexion sur les responsabilités des journalistes dans leur exposé d'œuvres, destinée à soutenir la liberté de la philosophie », dans laquelle il fustige ceux pour qui l'écriture devient un gagne-pain et qui produisent une quantité d'opinions contradictoires et absurdes auxquelles la communauté des savants devrait s'opposer par

\footnotetext{
${ }^{1}$ Je remercie Vladimir Somov (St.-Pétersbourg) et Larissa Kondratieva (Moscou) pour leur aide lors de la préparation de cet article. Vladislav Rjéoutski et Vladimir Somov tiennent à remercier la Herzog August Bibliothek pour le soutien du projet (bourse accordée pour la consultation des fonds de la Bibliothèque).

${ }^{2}$ Commentarii de rebus in scïentia naturali et medicnia gestis, Leipzig, 1752, vol. II, p. 222-227.
} 
tous les moyens ${ }^{3}$. Cette introduction ne touchera pas à toutes les questions abordées dans les études publiées dans ce numéro. Je développerai seulement un thème qui passe comme un fil rouge dans tous les articles réunis dans ce numéro de Vivliofika : celui des influences que cette presse subit tout au long du XVIII ${ }^{\mathrm{e}}$ siècle. L'histoire qu'ils racontent est celle de la presse qui répond aux attentes des pouvoirs et qui sert de moyen de propagande (même si le mot est anachronique pour une bonne partie du XVIII ${ }^{\mathrm{e}}$ siècle $^{4}$ ), ce qui explique le titre de ce numéro : «La Presse sous influence $»^{5}$.

On voudrait cependant s'éloigner de clichés et ne pas voir partout les tentacules de la cour de Russie qui poursuit ses objectifs propres. Les Russes qui entrent en contact avec les journalistes des périodiques européens ne peuvent pas tous être qualifiés de personnages officiels et toutes les initiatives de ce genre ne s'expliquent pas par les ordres donnés de St.-Pétersbourg : comme on verra, les savants poursuivent les intérêts de leur corporation, les littérateurs tâchent de promouvoir leurs œuvres, les voyageurs nobles ont souvent en vue la promotion de leurs idées... Cependant, il existe entre toutes ces initiatives un air de similitude car elles ont toutes comme toile de fonds non seulement la reconnaissance des mérites de ces auteurs, mais aussi de ceux de la société russe dans son ensemble. De leur côté, les périodiques occidentaux n'échappent pas non plus aux pressions des autorités de leurs pays ou aux clichés qu'ils entretiennent et font vivre ${ }^{6}$.

Dans ce siècle, la Russie sort des « ténèbres » et parvient à occuper l'une des premières places en Europe. Il n'est donc pas étonnant que son image devienne un enjeu extrêmement important, pour les adversaires de la puissance russe bien sûr, mais aussi et surtout pour la Russie elle-même. Les Russes comprennent que leur admission au concert des nations européennes ne dépend pas seulement de l'état de la société russe, de son économie, de ses armées, de ses sciences, belles lettres et arts... Elle dépend également, et peut-être même plus, de l'opinion publique en Europe. Celle-ci est alors formée, dans une grande mesure, par la presse. Un Français expatrié en Russie au milieu du XVIII ${ }^{\mathrm{e}}$ siècle, auteur d'un texte polémique composé pour " la défense et l'illustration » de la Russie, prête à un de ses personnages, qui est russe, ces paroles : «Ne nous flattons pas mal à propos, il faut acheter, il faut même payer bien cher, l'histoire de sa nation, lorsqu'on veut

\footnotetext{
${ }^{3}$ « Рассуждение об обязанностях журналистов при изложении ими сочинений, предназначенное для поддержания свободы философии», М.В. Ломоносов, Полное собрание сочинений [« Réflexion sur les responsabilités des journalistes dans leur exposé d'œuvres, destinée à soutenir la liberté de la philosophie », Mikhaïl Lomonossov, Euvres complètes], vol. 3, p. 202-232. Ecrite en latin, cette « Réflexion " a été traduite en français et publiée dans la Nouvelle Bibliothèque germanique, Amsterdam, 1755, vol. 7, part. 2, p. 343-366. Voir, pour plus de détails, Е. Лебедев, Ломоносов [E. Lebedev, Lomonossov], Moscou, 2008, p. 462-467.

${ }^{4}$ Il commence à être appliqué en dehors du contexte religieux vers la fin du XVIII siècle, alors que le phénomène était déjà là depuis longtemps. Aujourd'hui, le mot est souvent utilisé par les chercheurs travaillant sur cette époque. Citons, à titre d'exemple : Thomas W. Perry, Public opinion, Propaganda and Politics in 18th-Century England: A Study of the Jew Bill of 1753, Harvard, Harvard University Press, 1962 ; Edmond Dziembowski, Ecrits sur le patriotisme, l'esprit public et la propagande au milieu du XVIII siècle [de] Gabriel-Francois Coyer et Jacob-Nicolas Moreau, La Rochelle : Rumeur des âges, 1997.

${ }^{5}$ Titre qu'on emprunte à un article de Georges Dulac, «L'image de la Russie dans les gazettes et les correspondances diplomatiques française et ses annexes (1774-1780) », Nouvelles, gazettes, mémoires secrets (1775-180o), Actes du colloque international, Karlstad, 17-20 septembre 1994, sous la dir. de Birgitta Berglund-Nilsson, Karlstad, Karlstad University Press, 2000, p. 71-88.

${ }^{6} \mathrm{Au} \mathrm{XVIII}{ }^{\mathrm{e}}$ siècle, rares sont les cas où la presse occidentale est utilisée par les Russes comme une plateforme d'expression libre qui n'est pas soumise à la censure des autorités russes, on n'abordera donc pas cette question ici, alors que, pour le XIX ${ }^{\mathrm{e}}$ siècle, cet aspect sera d'une importance capitale. Voir : Michel Cadot, La Russie dans la vie intellectuelle française, Paris, Fayard, 1967; Ф.Я. Прийма, «Герцен пропагандист и интерпретатор русской литературы на Западе», Русская литература на Западе. Статьи и разыскания [F.Ia. Priima, « Herzen comme propagandiste et commentateur de la littérature russe en Occident », La Littérature russe en Occident. Articles et recherches], p. 114-140.
} 
qu'elle fasse honneur ${ }^{7}$. L'argent, qui est bien sûr utilisé au XVIII ${ }^{\mathrm{e}}$ siècle, tout comme à notre époque, pour acheter les faveurs des journalistes, ne fait évidemment pas tout. Comme on verra dans les études réunies ici, l'image d'un pays comme la Russie, qui doit faire ses preuves, est gagnée aussi grâce à d'autres moyens : par l'intermédiaire des contacts humains et par l'intérêt et la curiosité des journalistes et du public européen pour cette société « neuve » qui les étonne et les fait réfléchir.

On montrera ici, par quelques exemples et sans prétendre à l'exhaustivité, quelles images de la Russie et de ses souverains les périodiques français ou francophones mettent en avant et quelle représentations de la Russie les autorités russes privilégient et essaient de promouvoir dans la presse. Dans un second temps, on se penchera sur la question des réseaux que les Russes mettent en place afin d'atteindre leurs objectifs.

\section{La presse sous influence?}

Au XVII ${ }^{\mathrm{e}}$ siècle, la presse européenne était déjà, pour la cour russe, une source importante d'information. Les journaux reçus à Moscou étaient utilisés pour compiler une sorte de "digest» manuscrit de périodiques européens, appelé Vesti-Kouranty, destiné au tsar et à son entourage. Mais, comme l'ont montré dernièrement les chercheurs, les périodiques francophones n'ont pratiquement pas été utilisés pour compiler ce journal. Pour la période allant de 1660 à 1670 , Ingrid Maier a répertorié aux Archives nationales russes des actes anciens (RGADA) 466 périodiques en allemand, 123 en hollandais, 28 en polonais et 1 en Latin. A part une ou deux exceptions, les périodiques francophones sont utilisés seulement à partir de 1693, reflet sans doute de la méconnaissance presque totale du français dans la Russie de cette époque et de l'éloignement culturel des deux pays ${ }^{8}$.

C'est surtout avec l'avènement de Pierre le Grand que les pouvoirs russes commencent à utiliser la presse comme outil de " propagande » et à faire attention à ce qui se dit dans les journaux occidentaux sur la Russie et ses souverains. En témoignent par exemple les demandes réitérées de la part de Pierre $\mathrm{I}^{\mathrm{er}}$ adressées aux autorités de Hambourg afin de museler les journalistes de cette ville. En novembre 1701, une première requête russe exige que les pouvoirs hambourgeois interdisent de publier des « articles outrageant pour l'Etat russe $»{ }^{9}$. Une autre demande similaire est adressée en mai 1705 : les Russes insistent pour qu'aucune des villes se trouvant sous la domination de Hambourg ne publie «aucun mensonge contre l'Etat russe ${ }^{10}$. A cette époque, où la Russie commence tout juste à apparaître sur la scène européenne, il est difficile pour les Russes de construire l'image de leur pays en Occident, d'une part parce que leur pays est très éloigné de l'Europe occidentale, non seulement géographiquement, mais aussi mentalement ; d'autre part, à cause de la persistance de clichés construits par des voyageurs au cours des XVI ${ }^{\mathrm{e}}$ et XVII siècle, qui décrivent la Russie en termes de tyrannie, de superstition, de mœurs et de

\footnotetext{
${ }^{7}$ [Chevalier Desessart], « Voyageur moscovite ou Lettres russes », Bibliothèque nationale de Russie, Mss, Fr. Q XV 38, f $^{\circ} 15$.

${ }^{8}$ Вести-Куранты. 1656 г., 1660-1662 г2., 1664-1670 г2.: Иностранные оригиналы к русским текстам [Vesti-Kouranty. 1656, 1660-1662, 1664-1670: les originaux étrangers des textes russes], vol. 2, préparé par Ingrid Maier, Moscou, Yazyki slavianskikh koultour, 2008.

9 Archives nationales russes des actes anciens (infra - RGADA), fonds 44 (Relations de la Russie avec Hambourg), $1701, \mathrm{n}^{\circ}$.

${ }^{10}$ «никаких против Российскаго государства пасквилей непечатать». RGADA, fonds 44 (Relations de la Russie avec Hambourg), $1705, n^{\circ} 1$.
} 
pratiques barbares ${ }^{11}$. Le secrétaire de l'ambassade russe à Paris, Grigori Volkov, s'en rend parfaitement compte, il écrit en 1711 que le peuple français « est tout entier hostile à la Russie » et que " quelques bonnes que soient les nouvelles d'ici [de la Russie - V.R.], on ne veut pas les écouter ; qu'on ne les laisse pas publier dans les gazettes ; qu'il serait peutêtre avantageux de gagner les rédacteurs des journaux, afin qu'ils impriment les nouvelles qui nous sont favorables $»^{12}$.

A cette époque, les agents littéraires russes approchent des périodiques occidentaux publiés en différentes langues. Ainsi, sous le règne de Pierre le Grand, le baron Heinrich von Huyssen publie toute une série d'articles dans le journal Acta Eruditorum (1682-1782), qui sort en latin à Leipzig ${ }^{13}$. Les Acta Eruditorum étaient l'un des périodiques européens les plus influents parmi ceux qui publiaient des nouvelles de la vie scientifique. En 1705, il annonce qu'il existe à Moscou une école organisée par des jésuites dans laquelle de jeunes élèves russes apprennent le latin, les mathématiques et les "sciences militaires ${ }^{14}$. On pourrait penser que les autorités russes, à moins que ce ne soit l'initiative de Huyssen luimême, considéraient l'existence d'une telle école, même dirigée par des jésuites, comme une occasion de montrer le développement de l'éducation en Russie, qui n'était plus ce royaume d'ignorance dont parlaient les voyageurs occidentaux découvrant la Russie du $\mathrm{XVI}^{\mathrm{e}}$ et $\mathrm{du} \mathrm{XVII}^{\mathrm{e}}$ siècles. Les Nova Acta Eruditorum publient nombre d'articles scientifiques signés par des savants pétersbourgeois. Cela contribue évidemment à augmenter le prestige de l'Académie de Pétersbourg et, indirectement, à améliorer l'image de la Russie. Le même Huyssen établit des relations avec d'autres périodiques et journalistes avec l'objectif de leur faire écrire des articles à la gloire de l'Etat russe. C'est notamment le cas de l'Europäische Fama, à Leipzig, qui publie en effet plusieurs articles favorables aux Russes ${ }^{15}$. L'Europäische Fama entre parfois en polémique avec d'autres périodiques (par exemple, avec le Mercure historique, les Lettres historiques, l'Esprit des cours de l'Europe) en défendant l'honneur des armées russes ${ }^{16}$. Ce périodique publie aussi des portraits d'hommes d'Etat russes accompagnés d'explications qui soulignent leurs mérites ${ }^{17}$, mais aussi des vers en français, allemand et latin en l'honneur du tsar, des descriptions d'entrées solennelles du tsar et de son armée à Moscou et à SaintPétersbourg, etc. Huyssen ne se limite pas à initier des publications dans la presse, il fait élire à la société savante berlinoise des sujets russes ou des étrangers se trouvant au

\footnotetext{
${ }^{11}$ Voir par exemple, pour les opinions des voyageurs français uniquement, Michel Mervaud et Jean-Claude Roberti, Une infinie brutalité. L'image de la Russie dans la France des XVI et XVII siècles, Paris, IMSECO, Institut d'études slaves, 1991. Les vues des Français concordent en grande partie avec ce qu'écrivent les Anglais et les Allemands sur la Russie de la même époque.

${ }^{12}$ Cité d'après A. Rambaud, Recueil des instructions aux ambassadeurs et ministres de France depuis les traités de Westphalie jusqu'à la Révolution française, t. VIII-IX, Russie, Paris, 1890, p. 129.

${ }^{13}$ Selon l'auteur d'une étude sur ce journal, Huyssen y publie des articles à partir de 1714. H. Laeven, The Acta Eruditorum under the editorship of Otto Mencke (1644-1707): the history of an international learned journal between 1682 and 1707, Amsterdam, APA - Holland University press, 1990, p. 114. Cependant, on trouve déjà un article de lui en 1705, voir plus loin. Sur Huyssen, voir surtout Svetlana Korzun, Heinrich von Huyssen (1666-1739). Prinzenerzieher, Diplomat und Publizist in den Diensten Zar Peters I., des Großen, Wiesbaden : Harrassowitz, 2013.

${ }^{14}$ А.В. Флоровский, «Латинские школы в России в эпоху Петра I», XVIII век [A.V. Florovski, « Les écoles latines en Russie à l'époque de Pierre ${ }^{\mathrm{er}}{ }^{\prime}, X V I I I^{e}$ siècle], vol. 5, Moscou-Leningrad, Izd. AN SSSR, 1962, p. 316-335, ici p. 321 ; Acta Eruditorum, août 1705, Lipsiae, p. 389, etc.

${ }^{15}$ Die europäische Fama, welche den gegenwärtigen Zustand der vornehmsten Höfe entdecket. Voir à ce sujet П. Пекарский, Наука и литература в России при Петре Великом [Р. Pékarski, La science et la littérature en Russie sous Pierre le Grand], vol. 1, Saint-Pétersbourg, Izd. Akademii naouk, 1870, p. 94-95.

${ }^{16}$ Voir par exemple Europäische Fama, 1706, XLIII, p. 495, etc., mentionné dans: П. Пекарский, Наука и литература в России, op.cit., p. 94-95.

${ }^{17}$ Europäische Fama, 1706, XLIX, p. 533, voir П. Пекарский, Наука и литература в России, ор.cit., p. 95.
} 
service de la Russie, tâche de faire traduire et de publier leurs œuvres (par exemple, celle de l'évêque Gavriil Boujinski et celle du prince Demetrius Kantemir, père du poète et diplomate Antioche Kantemir) ; il est aussi à l'origine de quelques brochures qui présentent les affaires russes sous leur meilleur jour ${ }^{18}$. Ainsi, dans une de ces brochures datée de l'année $1706^{19}$, à côté des informations sur la géographie et l'histoire de la Moscovie, on trouve une description du plan d'études compilé par Huyssen pour l'héritier du trône russe : ce programme, qui se distingue par son aspect humaniste et européen et qui commence par un rappel de l'importance du français dans l'éducation d'un prince, est évidemment destiné à montrer que les souverains russes ne sont nullement étrangers à la culture européenne et que l'héritier du tsar s'apprête à devenir un souverain éclairé. Ces informations pouvaient à leur tour être empruntées par des périodiques comme c'était le cas de Welt und Staats Spiegel ${ }^{20}$.

Dès l'époque de Pierre le Grand, les périodiques en langue française sont parmi les plus utilisés par les Russes, le français étant l'un des principaux véhicules de la parole écrite sur le continent européen ${ }^{21}$. Des gazettes et journaux francophones se répandent dans presque tous les pays européens : les pays germanophones, l'Angleterre et surtout la République des Sept Provinces Unies (ou la Hollande). En Hollande, on contrefait même des périodiques français, voire des périodiques hollandais de langue française qui jouissent d'une grande popularité parmi les lecteurs. Avant 1765, Hambourg à lui seul compte une dizaine de titres de presse en français ${ }^{22}$.

Il n'est pas étonnant que, dès son apparition en 1720 , un autre périodique allemand proche par sa teneur des Acta Eruditorum, mais publié en français, à savoir la Bibliothèque germanique ${ }^{23}$, attire les regards des savants et des agents littéraires russes. Des nouvelles concernant la Russie commencent à y être régulièrement insérées. La faveur croissante du français se reflète dans les manières d'utiliser cette presse par certains littérateurs russes. $\mathrm{Si}$, en 1753, Gottsched publie dans son périodique Das Neueste aus der anmuthigen Gelehrsamkeit une recension fort louangeuse de Sinav et Trouvore d'Alexandre Soumarokov ${ }^{24}$ et, en 1755, une autre recension de la même pièce est publiée par un

\footnotetext{
${ }^{18}$ Ibid. X. Грасхофф, « Из истории связей берлинского общества наук с Россией в 20-х годах XVIII века », 18 век [Helmut Grasshoff, « De l'histoire des relations entre la Société des sciences de Berlin avec la Russie dans les années $1720 », 18^{e}$ siècle], vol. 7, Moscou-Leningrad, Naouka, 1966, p. 59-65.

${ }^{19}$ Relation von dem gegenwärtigen Zustande des Moscowitischen Reichs, Francfort, 1706.

${ }^{20}$ П. Пекарский, Наука и литература в России, ор.cit., p. 97. Voir d'autres exemples de ce genre dans ce livre, notamment l'histoire de la réfutation par Huyssen d'un ouvrage très critique à la Russie écrit par un ancien précepteur du prince héritier, Neugebauer, ibid., p. 98-99.

${ }^{21}$ Sur le français en Europe à cette époque, voir Ferdinand Brunot, Histoire de la langue française des origines à 1900, 13 vol., Paris : Librairie Armand Colin, 1905-53, 1969-79, en particulier vol. 5 (Le français en France et hors de France au XVII siècle, 1917) et 8 (Le français hors de France au XVIII ${ }^{e}$ siècle, partie 1, 1934, et 2, 1935). Voir aussi : European Francophonie. The Social, Political and Cultural History of an International Prestige Language, sous la dir. de Vladislav Rjéoutski, Gesine Argent et Derek Offord, Oxford, Peter Lang, 2014.

${ }^{22}$ Voir par exemple Holger Böning, Deutsche Press. Bibliographische Handbücher zur Geschichte der deutschsprachigen periodischen Presse von den Anfängen bis 1815, Band 1.1, Holger Böning, Emmy Moepps, Hamburg. Kommentierte Bibliographie der Zeitungen, Zeitschriften, Intelligenzblätter, Kalender und Almanachs sowie biographische Hinweise zu Herausgebern, Verlegern und Druckern periodischer Schriften, von den Anfägnen bis 1765, Stuttgart, Frommann-Holzburg, 1996.

${ }^{23}$ Voir la notice «Bibliothèque germanique » par Jürgen Kämmerer, Dictionnaire des journaux, sous la dir. de Jean Sgard, édition électronique : http://dictionnaire-journaux.gazettes18e.fr/journal/o163-bibliothequegermanique (consulté le 8 novembre 2016).

${ }^{24}$ Das Neueste aus der anmuthigen Gelehrsamkeit, 1753, p. 684-91.
} 
périodique francophone influent des Lumières, le Journal étranger ${ }^{25}$, c'est cette dernière qui est traduite et publiée dans le seul périodique littéraire en langue russe, Ejemessiatchnyé sotchineniia ${ }^{26}$, confirmant ainsi que la célébrité de Soumarokov passe les frontières de la Russie ${ }^{27}$. L'objectif de ce recours à la presse francophone européenne est aussi évident dans les publications que Nikolaï Karamzine insère dans le Spectateur du Nord à la fin du siècle (voir à ce sujet l'article de Vladimir Somov).

Dans la presse francophone occidentale en général, les nouvelles sur la Russie ne sont pas encore très fréquentes à l'époque de Pierre $\mathrm{I}^{\mathrm{er}}$, comme le montre l'article d'Edwin van Meerkerk publié dans ce numéro : même les Nouvelles littéraires, l'un des journaux les plus informés et ayant le réseau des journalistes le plus étendu, ne fait pas beaucoup attention à la Russie, qui se trouve, dans l'imaginaire des occidentaux, en dehors du monde civilisé. Si l'image de la Russie commence à changer dans la presse de cette époque, c'est souvent en relation avec les visites de Pierre le Grand en Europe occidentale, comme le montre encore le même article. Les enjeux de l'influence russe incluent la publication de nouvelles politiques favorables à la Russie, particulièrement celles qui concernent les victoires militaires (l'histoire de la diffusion des nouvelles sur la victoire de Poltava est à cet égard exemplaire), mais aussi la diffusion de nouvelles proprement culturelles telles que la publication de livres en Russie (sur ces deux questions, voir l'article de Nicolaï Kopanev).

Mais la Russie devient parfois un objet de débat non pas au sujet des batailles militaires, mais à cause de la curiosité pour ces nouveaux territoires. C'est l'expression à la fois d'un enthousiasme de la science dix-huitiémiste pour des contrées inexplorées et de l'intérêt des gens des Lumières pour le «bon sauvage». On voit cet intérêt particulièrement dans le cas de la Bibliothèque germanique (1720-1740) et de la Nouvelle Bibliothèque germanique (1746-1759). Les nouvelles sur les livres publiés en Russie servent non seulement à répandre des informations proprement scientifiques partout en Europe, mais améliorent également l'image de la Russie : d'une contrée barbare, la Moscovie devient un pays où des livres présentant de l'intérêt pour toute l'Europe sont publiés. Parmi les auteurs traduits en russe et mentionnés dans la Bibliothèque germanique, on trouve par exemple Pufendorf, ce qui doit confirmer l'intérêt des Russes pour les idées politiques européennes ${ }^{28}$. La Nouvelle Bibliothèque germanique continue cette tradition, en faisant attention à la production scientifique de l'Académie des sciences pétersbourgeoise. Les publications de l'Académie russe reçoivent un très bon accueil dans ces deux périodiques et dans le Journal littéraire (1741-1742), qui a été un intermède entre les deux Bibliothèque. En témoignent non seulement le ton, mais également la longueur des articles consacrés à l'Académie de Saint-Pétersbourg et à ses productions : ainsi, l'analyse du volume 6 des Mémoires de l'Académie des Sciences de Petersbourg (1738) s'étend sur vingt-cinq pages: le Journal littéraire reproduit la table des matières du

\footnotetext{
${ }^{25}$ Journal Etranger, 1755, april, p. 114-56.

${ }^{26}$ Ежемесячные сочинения [Euvres mensuelles], 1758, vol. II, p. 507, etc.

${ }^{27}$ Sur l'usage de la presse par Soumarokov, voir Vladislav Rjéoutski et Derek Offord, «Translation and propaganda in the mid-eighteenth century: French versions of Sumarokov's tragedy Sinav and Truvor ", Online corpus of documents, à l'adresse: https://frinru.ilrt.bris.ac.uk/introduction/translation-andpropaganda-mid-eighteenth-century-french-versions-sumarokov\%E2\%80\%9gs-tragedy\# edn13

${ }^{28}$ Margarita Voïtenko, La République des Lettres et l'Empire Russe : "transplantation» des Lumières en Russie dans la 1-re moitié du XVIII siècle à travers la revue "Bibliothèque Germanique », 1720-1741, St.Pétersbourg, 1998. Nous n'indiquons pas les pages de ce mémoire car nous avons utilisé une version électronique avec les pages non numérotées. Voir aussi Margarita Voitenko, La Présentation de la Russie dans la presse francophone de la première moitié du XVIII siècle, mémoire présenté pour le DEA, EHESS, Paris, 1999.
} 
journal savant pétersbourgeois et donne une analyse détaillée des mémoires des membres de l'Académie : Euler, Weitbrecht, Bayer, etc. ${ }^{29}$

Ce dernier mémoire est particulièrement intéressant du point de vue de l'image de la Russie : Bayer affirme que la nation russe est très ancienne et que, déjà au $\mathrm{IX}^{\mathrm{e}}$ siècle, elle menaçait Constantinople ; il donne aussi des informations sur le baptême des "Russes » (il est remarquable qu'on parle seulement des «Russes » ou «Russiens » à ce propos) et rappelle leur appartenance à la chrétienté. Cet exposé est conclu par cette remarque :

[...] on ne doit pas s'étonner, qu'il se soit trouvé à Constantinople des gens assez habiles dans la langue Esclavonne, pour instruire les Russiens ; puisque depuis long-temps il y avoit des personnes de cette Nation employées dans les affaires Civiles \& Militaires [de Constantinople $]^{30}$.

On a donc l'impression que la Russie rayonnait déjà à cette époque bien au-delà de ses frontières. On trouve dans le même volume un article sur les Observations Astronomiques de Mr. De l'Isle pour l'année 1738 et un autre sur la Description et représentation exacte de la Maison de Glace par un autre académicien pétersbourgeois, Georg Wolfgang $\mathrm{Krafft}^{31}$. Ce palais est présenté comme une œuvre inouïe d'architecture et de génie civil. Le journal rapporte aussi les débats scientifiques menés par les savants pétersbourgeois et donne d'autres nouvelles sur les membres de l'Académie russe ${ }^{32}$. Les livres traitant de la vie de Pierre le Grand, sortis en Russie, sont particulièrement appréciés. En général, Pierre est présenté sur les pages de ces périodiques comme un «héros ». Les journalistes approuvent les mesures prises par l'empereur à l'égard de l'Eglise orthodoxe, regardant l'orthodoxie comme un assemblage de coutumes qui doivent être améliorées par la volonté du monarque éclairé. La Russie, presqu'inconnue en Europe avant Pierre le Grand, commence donc à peser dans les affaires de l'Europe, selon les journalistes de la Bibliothèque germanique ${ }^{33}$. Cette attention au développement de la science en Russie se poursuit dans la deuxième moitié du siècle et contribue ainsi à consolider la vision de la Russie comme d'un pays civilisé. Ainsi, l'Esprit des journaux, édité depuis 1772 à Liège,

\footnotetext{
${ }^{29}$ Journal littéraire d'Allemagne, de Suisse et du Nort, op.cit., 1743, t. 2, ${ }^{\text {re }}$ partie, p. 36-61.

${ }^{30}$ Journal littéraire d'Allemagne, de Suisse et du Nort, op.cit., 1743, t. 2, re partie, p. 61.

${ }^{31}$ Description et représentation exacte de la Maison de Glace construite à St. Petersbourg, au mois de Janvier 1740 [...] Composée \& publiée en faveur des Amateurs de l'Histoire Naturelle par George Wolfgang Krafft, Membre de l'Acad. Imp. de St. Pet. et Professeur de Physique, Traduit de l'Allemand par Pierre Louis le Roy, Membre de l'Ac. Imp. De S.P. \& Prof. d'Histoire, A St. Petersbourg, De l'Impr. de l'Ac. des Sciences, 1741, p. 32 ; Journal littéraire d'Allemagne, de Suisse et du Nort, op.cit., 1743, t. 2, ${ }^{\mathrm{re}}$ partie, p. 62-67.

32 «M. Gleditsch ayant écrit contre l'Examen du Sistème Botanique de M. Hinnaeus, par M.Siegesbeck, celuici vient de lui répondre, \& de se défendre, par une Brochure intitulée : Vaniloquentiae Botanicae Specimen. M. Siegesbeck persiste à nier qu'il y ait, entre les Plantes, diversité de Sexe, \& donne à ceux qui soutiennent cette diversité le nom de Sexualistes. », Ibid., p. 182. Ou encore, dans le même volume, $2^{\text {nde }}$ partie, p. 429, les nouvelles sur la mort de Delisle de la Croyère avec un rappel de ses voyages à Arkhangelsk, à Kola et dans la Laponie et l'intérêt de ses observations astronomiques «fort importantes»; l'affaire de Schumacher qui, «après s'être justifié de plusieurs accusations très graves, vient d'être rétabli par S.M.I. dans sa charge de Directeur », etc.

${ }^{33}$ Voïtenko, La République des Lettres et l'Empire Russe, op. cit.
} 
puis à Bruxelles ${ }^{34}$, consacre plusieurs articles aux expéditions organisées par l'Académie impériale des sciences et aux découvertes scientifiques faites en Russie ${ }^{35}$.

La politique d'influence visant la création dans les différents pays européens d'une opinion publique favorable à la Russie est, on l'a vu, menée par les autorités russes à partir du règne de Pierre $\mathrm{I}^{\mathrm{er}}$. Elle connaît ses pages brillantes et ses échecs cuisants. Les raisons de ces échecs sont multiples.

Premièrement, les journalistes continuent de suivre les Fontenelle et les Weber dans leur idée de la Russie d'avant Pierre et du peuple russe qui montre un " attachement extrême " à l'ignorance et à ses anciennes coutumes, " quelque absurdes qu'elles puissent être $»^{36}$ et il n'est pas rare qu'ils transposent ces caractéristiques sur la société russe de leur temps. Comme l'a montré Michel Mervaud, même à l'époque de Catherine II, qui a tant fait pour séduire l'opinion occidentale, la presse française oscille entre l'admiration de la politique menée par l'impératrice russe et les vieux clichés provenant des relations de voyageurs occidentaux ayant observé la Russie des $\mathrm{XVI}^{\mathrm{e}}$ et $\mathrm{XVII}^{\mathrm{e}}$ siècles. Le cas du supplice du knout et de l'honneur des Russes, étudié par Michel Mervaud, est particulièrement éclairant à cet égard. L'Encyclopédie, qui n'est pourtant pas hostile à la Russie, publie l'article « knout ou knut », consacré à une punition infamante pratiquée en Russie. Cet article aurait pu passer inaperçu si l'auteur, se basant sur une information ancienne tirée certainement d'Oléarius ou de John Perry, n'avait pas précisé que ce supplice "n'est point tenu pour un deshonneur » en Russie. Un Russe, député de la Commission des lois convoquée par Catherine II, y réagit en publiant une réfutation vigoureuse dans le Journal encyclopédique ${ }^{37}$. Cependant, le même Journal encyclopédique, pourtant proche des philosophes et de Diderot ${ }^{38}$, dans un compte rendu de l'ouvrage de l'abbé Chappe d'Auteroche, qui reprenait les mêmes clichés et qui a tellement irrité Catherine II, écrit en 1770 :

Les Russes, lit-on dans le Journal encyclopédique, quel que soit leur rang, leurs qualités, sont traités en esclaves et chez eux, les châtiments ni les supplices même, ne sont regardés que comme de simples corrections qui ne deshonorent point : car enfin, quel seroit le moyen de deshonorer des esclaves... ${ }^{39}$

Deuxièmement, beaucoup de journalistes ne reprennent pas aveuglement les clichés de la Russie barbare ni ceux du «mirage russe», bien plus récents (même si,

\footnotetext{
${ }^{34}$ Voir la notice « Esprit des journaux », par Philippe Vanden Broeck, dans le Dictionnaire des journaux, op. cit., à l'adresse http://dictionnaire-journaux.gazettes18e.fr/journal/0397-lesprit-des-journaux (consulté le 14 novembre 2016).

${ }^{35}$ Alexandre Stroev, « La Russie dans l'Esprit des journaux (années 1770-1780) », L'Esprit des journaux : un périodique européen au XVIII ${ }^{e}$ siècle. Actes du colloque « Diffusion et transfert de la modernité dans l'Esprit des journaux » organisé par le Groupe d'études du XVIII' siècle de l'université de Liège (16-17 février 2009), sous la dir. de Daniel Droixhe, avec la coll. de Muriel Collard, Bruxelles, Le Cri, 2009, p. 263-282, ici p. 273. ${ }^{36}$ La Bibliothèque germanique, t. VIII, p. 188, cité d'après Voitenko, La Présentation de la Russie dans la presse francophone, op. cit., p. 44.

${ }^{37}$ Cette « Lettre d'un Russe » est publiée dans le Journal encyclopédique le 15 septembre 1773. Voir Michel Mervaud, « Le knout et l'honneur des Russes (à propos de deux articles de l'Encyclopédie) », Recherches sur Diderot et sur l'Encyclopédie, 1993, vol. 14(1), p. 111-124, ici p. 115.

${ }^{38}$ Voir la notice «Journal encyclopédique », par Jacques Wafner, Dictionnaire des journaux, op. cit., à l'adresse : http://dictionnaire-journaux.gazettesi8e.fr/journal/o73o-le-journal-encyclopedique (consulté le 12 novembre 2016).

${ }^{39}$ Journal encyclopédique, octobre 177o, t. VII, p. 45. Cité d'après Mervaud, « Le knout et l'honneur des Russes », art. cit., p. 119.
} 
généralement, ils présentent Catherine II comme une souveraine éclairée). Ainsi, on peut lire dans l'Esprit des journaux :

Les paysans russes sont malheureux ; ils travaillent autant qu'ils peuvent, et tout ce qu'ils recueillent leur est presque toujours enlevé par le premier gentilhomme du voisinage, qui juge à propos de les voler et de les battre. L'impératrice de Russie s'occupe des moyens d'extirper ces abus ${ }^{40}$.

Les journalistes critiquent notamment l'un des créateurs du « mirage russe », Voltaire, et s'emparent de la discussion sur le servage, l'absence de liberté et la transplantation des sciences et des arts dans l'empire de Russie, ayant souvent recourt aux idées les plus diverses, comme dans ce passage, qui fait référence à la théorie des climats de Montesquieu tout en l'intégrant dans un discours que développent alors les physiocrates et Diderot :

Où règne le despotisme, il ne peut y avoir d'émulation, et l'imagination est sans chaleur dans un climat glacé. Quand le tsar [Pierre $\mathrm{I}^{\mathrm{er}}$ ] voulut peupler d'oiseaux la triste forêt au travers de laquelle passe la Neva, il en fit transporter de nombreuses colonies des parties méridionales de son Empire. Jamais on n'entendit le chant mélodieux de ces nouveaux hôtes ; tous périrent en peu de temps, sans essayer de laisser de leur postérité. Il en serait de même du génie de ces artistes célèbres que produisent l'Italie et la France ; transportés en Russie, ils y seraient sans force et sans chaleur ${ }^{41}$.

L'Esprit des journaux publie ce mémoire en 1772, l'année où la Correspondance littéraire insère un fragment de Diderot intitulé "Qu'il faut commencer par le commencement », dans lequel celui-ci expose des idées similaires ${ }^{42}$. Certains journaux, comme le Journal encyclopédique ou le même Esprit des journaux publient également des avis de ceux qui connaissent bien la Russie comme ceux de l'historien Pierre-Charles Levesque qui a passé de nombreuses années dans ce pays. Les idées de Levesque sur la Russie échappent aux dichotomies simplistes ${ }^{43}$.

Troisièmement, les journalistes ne regardent pas seulement du côté de la Russie. Sous le règne de Catherine II, le poids de la Russie dans les affaires européennes en fait un pays respecté, voire redouté, c'est ce qui déplaît à certaines puissances européennes, avant tout à la France. Les années 1770, avec la guerre russo-turque, la révolte de Pougatchev et le partage de la Pologne, sont à cet égard particulièrement propices aux combats par plumes interposées, comme l'a montré Georges Dulac ${ }^{44}$. L'importance des gazettes dans les affaires politiques est d'autant plus accrue que les souverains et les politiciens les lisent, comme le fait Catherine II. Les informations données par la presse sont également prises en compte par des financiers: ce n'est pas un hasard si les banquiers hollandais continuent de regarder la Russie comme un pays instable ce qui complique le prêt des capitaux si nécessaires à la Russie pendant sa guerre contre les Turcs... ${ }^{45}$ Dans cette époque marquée par la propagande anti-russe du gouvernement français, le diplomate

\footnotetext{
${ }^{40}$ J. Marshall, Voyages en Hollande, Esprit des journaux, septembre 1772, t. III, p. 108, cité d'après Stroev, « La Russie dans l'Esprit des journaux », art. cit., p. 265.

${ }^{41}$ «Extrait d'un mémoire sur la Russie », Esprit des journaux, 30 novembre 1772, t. V, partie II, p. 138, cité d'après Stroev, « La Russie dans l'Esprit des journaux », art. cit., p. 268.

${ }^{42}$ Stroev, «La Russie dans l'Esprit des journaux », art. cit., p. 268.

${ }^{43}$ Stroev, «La Russie dans l'Esprit des journaux», art. cit., p. 270-271.

${ }^{44}$ Dulac, « L’image de la Russie dans les gazettes », art. cit., p. 71-88.

${ }^{45}$ Dulac, « L'image de la Russie dans les gazettes », art. cit., p. 73.
} 
russe à La Haye, le prince Dmitri Golitsyne, approche le Courrier du Bas-Rhin de Manzon et les deux gazettes des Deux-Ponts pour que ces périodiques jettent un regard favorable sur les affaires russes. Il réussit provisoirement à faire pencher la balance du côté de la Russie dans le Courrier du Bas-Rhin. Ce périodique reste longtemps favorable aux Russes, parfois de façon exagérée. Le Courrier remplit ses pages de descriptions des fastes de la cour de Pétersbourg, parle des institutions éducatives de Catherine II (le Corps des cadets nobles et l'Institut Smolny), de la statue de Pierre le Grand fondue par Falconet, etc. "L'ensemble, écrit Georges Dulac, compose à l'évidence une image séduisante, qui semble destinée à corriger ou à compenser la représentation très sombre que donnent du pays les gazettes hostiles, dont la palette est généralement très proche de celle qu'affectionne le ministre de France à Pétersbourg ${ }^{46}$. Le prince Golitsyne fait également jouer ses relations à Deux-Ponts et parle dans sa correspondance diplomatique du plaisir qu'il aurait « de voir leur gazette politique ne donner que des nouvelles sûres sur des événements du jour et des travaux de notre auguste impératrice ; et la littéraire, faire connaître à quel point les lettres sont cultivées sous sa protection ${ }^{47}$. Cependant, il ne réussit pas vraiment dans cette mission car la Gazette des Deux-Ponts se trouve sous l'influence de la France. Ainsi, à quelques mois de la paix victorieuse que la Russie va conclure avec la Turquie, la Gazette minimise les succès de l'armée russe, position qui ressemble beaucoup à ce qu'écrit au même moment le représentant diplomatique de la France à Saint-Pétersbourg, Durand de Distroff. A la même époque, sur l'initiative du duc Etienne-François de Choiseul, la Gazette de France est remplie de nouvelles de la même teneur qui suscitent le mécontentement du chargé d'affaires russe en France N. Khotinski qui accuse la presse française de soutenir les Turcs contre la Russie ${ }^{48}$. D'autres sujets abordés par la Gazette des Deux-Ponts comprennent les succès de Pougatchev, la censure exercée en Russie, les affaires de la Pologne, les colonies de la Volga, les efforts législatifs de Catherine II... ${ }^{49} \mathrm{Si}$ le ton général à l'égard de la Russie reste négatif, on y voit parfois des analyses perspicaces des initiatives de Catherine II qui s'éloignent des clichés de propagande, comme le remarque Georges Dulac. Ainsi, quand la Gazette des Deux-Ponts jette en 1774 son regard sur le Nakaz, « ce plan le plus sage et le plus beau qui ait été jamais conçu par un souverain, et qui l'a été au milieu du despotisme ", et sur les résultats des efforts législatifs de Catherine, elle attire l'attention de ses lecteurs sur le fait que la diversité des peuples habitant ce grand empire, avec leurs différentes traditions et coutumes, pose un obstacle considérable à la réalisation de ce projet, mais que Catherine II, qui a voulu «mettre des lois à la place de la volonté arbitraire de ses prédécesseurs ", ne doit pas «abandonner son ouvrage » : "son génie lui en fournira les moyens, et elle se doit à elle-même d'achever ce qu'elle a commencé ${ }^{50}$. Par ailleurs, comme le note à juste titre Georges Dulac, les succès des armes russes, les expéditions organisées par l'Académie des sciences, les initiatives législatives de Catherine II, tout cela prête peu à la malveillance : les journalistes doivent satisfaire la curiosité du public qui est de plus en plus avide des nouvelles sur la Russie et, «les informations les plus marquantes à lui offrir concernent généralement ces faits qui « éblouissent » l'étranger,

\footnotetext{
${ }^{46}$ Dulac, « L'image de la Russie dans les gazettes », art. cit., p. 76.

${ }^{47}$ Cité d'après Dulac, « L'image de la Russie dans les gazettes », art. cit., p. 74.

$4^{8}$ А.А. Митрофанов, Н.В. Промыслов, Е.А. Прусская, «Русская угроза во французской прессе конца XVIII - начала XIX в.», Французский ежегодник 2015 [A.A. Mitrofanov, N.V. Promyslov, E.A. Prousskaïa, «La menace russe dans la presse française de la fin du XVIII ${ }^{\mathrm{e}}$ et du début du XIX ${ }^{\mathrm{e}}$ siècles », Annuaire d'études françaises 2015], Moscou, Institut d'histoire universelle, 2015, p. 343-391, ici p. 346.

49 Dulac, «L'image de la Russie dans les gazettes », art. cit., p. 75-76 ; et l'article de Georges Dulac publié dans ce numéro.

${ }^{50}$ Cité d'après Dulac, « L’image de la Russie dans les gazettes », art. cit., p. 81.
} 
comme le constatent avec dépit les diplomates, parce qu'ils présentent, outre l'attrait de la nouveauté, une ampleur de perspective que peu d'autres nouvelles comportent en Occident $»^{51}$.

Les périodiques francophones de Hambourg et de Brunswick édités à la fin du XVIII ${ }^{\mathrm{e}}$ siècle abordent régulièrement les thèmes russes. On y trouve des informations sur les monarques russes (Pierre $\mathrm{I}^{\mathrm{er}}$, Pierre III, Catherine II, Paul $\mathrm{I}^{\mathrm{er}}$ ), sur la vie de la cour impériale, sur les succès des armées russes (Souvorov), sur les lettres russes (Karamzine, etc.), des comptes rendus d'ouvrages consacrés à la Russie (Rulhière, Castéra, Chantereau, Levesque, Laveaux, Masson, etc.). La presse des émigrés est souvent à l'écoute de Pétersbourg. Les relations difficiles entre l'empereur Paul $\mathrm{I}^{\mathrm{er}}$ et sa mère se reflètent, après la mort de celle-ci, dans ce qu'on peut lire sur Catherine II dans le Spectateur du Nord. En 1797, celui-ci écrit, à propos de Pierre III, cet empereur détrôné par sa femme qui monte sur le trône russe avec le nom de Catherine II :

L'Europe abusée [...] n'a jugé ce Prince que sur les rapports de ses mortels ennemis, où de leurs lâches partisans [...] Catherine II régna, et sa gloire remplit le monde. Des Philosophes en furent les héraults ; l'ami de vérité ne doit pas les contredire ; mais ne lui est-il pas permis de compter le nombre d'hommes, de femmes et d'enfants que, durant plus de trente années, cette gloire coûte à la Pologne, à la Suède, à la Turquie, à la Perse, et surtout à la Russie ? $5^{2}$

On y voit de la critique ouverte du « despotisme » de Catherine II ce qui, paradoxalement, rapproche ce journal émigré de ce que pouvait alors écrire la presse de la République française...

De son côté, la presse de la France républicaine se trouve évidemment aussi sous une forte influence idéologique. A l'époque de la Révolution, les stéréotypes de la «menace russe », nés à l'époque de Pierre le Grand et maintenus par les diplomates français tout au long du XVIII ${ }^{\mathrm{e}}$ siècle, retrouvent leur fraîcheur. Dès avant la Révolution, la Porte ottomane est regardée par la France comme capable de mettre un frein à l'avancement des Russes en Europe. Cette vision des choses continue à l'époque révolutionnaire comme le montre notamment l'analyse du Moniteur par Natalia Vochtchinskaïa (voir son article dans ce numéro). La presse révolutionnaire soutient la Suède, alliée traditionnelle de la France d'Ancien Régime, contre la Russie dans la guerre qui oppose les deux pays en 17881790. La Suède est chargée par les journalistes d'une mission presque sacrée de retenir les Russes. Les fantasmes de l'invasion possible de la France par les «barbares russes » trouvent leur expression dans les publications des périodiques, peurs consolidées par l'aide promise par Catherine II aux royalistes et à la coalition anti-française. En 1792, le Moniteur répand le bruit qu'après la Pologne, 15000 Russes vont se diriger vers la France ${ }^{53}$. Les nouvelles sur les dépenses de guerre qui ont presque ruiné la Russie ou sur l'état déplorable de l'armée russe revenant du sud sont censées minimiser la puissance des Russes et calmer les peurs des Français que cette presse travaille elle-même à entretenir. Le mythe de Catherine II, qui a transformé son empire en un royaume où fleurissent les sciences et les arts, développé par une bonne partie de la presse francophone en Europe, même celle qui se trouvait sous l'influence directe de Versailles, tend à s'effacer dans une bonne partie de la presse républicaine. Le discours invoquant le caractère «barbare » des Russes revient à nouveau, notamment comme explication des succès de l'armée russe, le

\footnotetext{
${ }^{51}$ Dulac, « L'image de la Russie dans les gazettes », art. cit., p. 85.

${ }^{52}$ Le Spectateur du Nord, $1797, \mathrm{n}^{\circ} 2$, p. 283-288.

53 Митрофанов, Промыслов, Прусская, «Русская угроза во французской прессе», art. cit., p. 351.
} 
« barbare » n'ayant pas peur de mourir et ne sentant pas la pitié54. Les nouvelles dans la presse des émigrés, qui se réjouit des succès des Russes, ne sont pas très différentes et sont nourries par des fantasmes similaires (voir l'article de Vladimir Somov). Dans cette perspective, la France républicaine est présentée dans la presse française comme une sorte de garant de la liberté des « nations libres » du continent européen. Les affaires de la Pologne offrent, comme vingt ans auparavant, une occasion d'opposer la Russie « despotique » et la Pologne « éprise de liberté ». Le portrait de Catherine II devient de plus en plus accablant (voir l'article de Natalia Vochtchinskaïa). La presse française des années 1793-1794 se trouve sous l'influence des montagnards, le discours de Robespierre, du 17 novembre 1793, sur la politique étrangère, qui dessine un portrait de la Russie et de sa souveraine, forme la ligne directrice pour cette presse ${ }^{55}$. En 1794, dans un discours célèbre à la Convention, Boissy d'Anglas reprend les vieux clichés en présentant la Russie à la fois comme faible ( " colosse aux pieds d'argile ») et comme agressive, envahissante et barbare (les Russes sont comparés aux hordes d'Attila). La presse reprend ce discours et le diffuse, cela ne manque pas de provoquer des réponses polémiques ${ }^{56}$.

Sous le Directoire, la teneur des publications de la presse française sur la Russie est très proche des analyses des Affaires étrangères françaises. Il est vrai que, même si la peur de l'invasion russe est très exagérée, elle se nourrit des succès réels des armées russes. Souvorov, à la tête de l'armée des «barbares du Nord», va hanter les esprits des journalistes français. Les témoins oculaires ayant connu la Russie soutiennent cette vision des choses $^{57}$. Ce n'est qu'après la sortie des Russes de la deuxième coalition que la « menace russe » cesse d'être si obsédante dans la presse française ${ }^{58}$. L'image d'une Russie barbare et despotique ne disparaît évidemment pas complètement, certains périodiques, comme le Journal des hommes libres de tous les pays, continuent à la véhiculer, quoiqu'avec moins d'ardeur.

Avec le Consulat, la presse proche du gouvernement change de ton et il se dessine alors une image bien plus positive de la Russie. Les actions du tsar et de ses ministres sont de nouveau louées ce qui reflète les espoirs de rapprochement entre les deux pays, de l'éloignement de la Russie de l'Angleterre et même de la création, avec la Russie, d'une nouvelle coalition contre la "perfide Albion». Apparaissent de nouveaux sujets, longtemps quasiment oubliés, tels que les progrès des belles-lettres en Russie. C'est au même moment que sont traduits de l'anglais et de l'allemand des livres sur la Russie qui vont dans le même sens et ce n'est certainement pas un hasard ${ }^{59}$. Se souciant de nouveau de l'intérêt du lecteur pour cet empire lointain et mystérieux, certains périodiques français adoptent même un ton d'exotisme exalté et admiratif. Cet article tiré du Journal des dames et des modes de l'année 1802 en est un exemple éloquent et un peu comique :

\footnotetext{
54 Митрофанов, Промыслов, Прусская, «Русская угроза во французской прессе», art. cit., p. $352-353$.

55 Митрофанов, Промыслов, Прусская, «Русская угроза во французской прессе», art. cit., p. 354.

${ }^{5}$ Par exemple, Epître du vieux cosmopolite Syrach à la Convention Nationale de France contenant l'examen du discours prononcé à la séance du 2 pluviose de l'an III par citoyen Boissy d'Anglas, En Sarmatie, 1795. Voir Митрофанов, Промыслов, Прусская, «Русская угроза во французской прессе», art. cit., p. 357.

57 Voir [Nicolas Fornerod], Coup d'œil sur l'état actuel de la Russie envisagée sous ses rapports physique, moral, économique, politique et militaire ou les Russes tels qu’ils sont. Par un ami de la Vérité, Lausanne, 1799. Voir l'analyse de ce pamphlet dans: André Bandelier, Vladislav Rjéoutski, «Fornerod «le républicain » : un précepteur hostile à la propagande tsariste », Le Précepteur francophone en Europe, XVII $X I X^{e}$ siècles, sous la dir. de Vladislav Rjéoutski et Alexandre Tchoudinov, Paris : L'Harmattan, 2013, p. 373390.

${ }^{8}$ Митрофанов, Промыслов, Прусская, «Русская угроза во французской прессе», art. cit., p. 361.

59 Митрофанов, Промыслов, Прусская, «Русская угроза во французской прессе», art. cit., p. 362-365. Sur l'évolution de l'image de la Russie dans la presse française sous Napoléon, voir cet article, p. 366-388.
} 
Deux époques intéressantes à Pétersbourg sont celles de la gelée et du débaclement. La communication est alors interrompue pour quelques jours entre les différentes isles que forme la superbe Néva, et qui composent la jeune et magnifique ville de Pierre Ier. [...] Une Dame de Paris frémiroit à l'idée de traverser, dans un carosse à six chevaux, un fleuve si large et si profond, sur des blocs de glace fragile ; mais à Pétersbourg il n'y a que quelques femmes craintives qui s'en effrayent. [...] En revenant d'un souper, d'un bal ou d'un spectacle pendant la nuit, enfermé chaudement au fond d'un carosse, dans une bonne pelisse, on oublie qu'on traverse un abime pendant près d'un quart de lieue : lorsque les glaces sont recouvertes par les neiges, et que les chemins sont battus, l'on ne s'appercevroit même pas qu'on est sur l'eau, si un retentissement sonore ne vous en avertissoit, et si vous n'étiez pas étonné de passer entre des lignes de vaisseaux qui semblent posés sur la neige, et qui forment sur la Néva des rues qui lui donnent l'air d'une ville d'une architecture singulière [...] L'époque où la Néva est gelée, est la plus brillante pour Petersbourg, et l'hyver y est la belle saison. Les communications sont établies partout ; tous les chemins sont bons ; les provisions, le gibier, la volaille arrivent en traineaux des extrémités de l'empire, et sur le marché, qui est pour cette ville ce qu'est pour Paris le quai de la Vallée [...] Au printemps, les glaçons de la Néva se détachent toutà-coup. L'on voit en un moment voguer des barques où glissoient les traineaux. Le canon de la forteresse annonce la débâcle, et la commandant, monté sur une superbe chaloupe, apporte à l'impératrice, qui, entourée de sa cour, l'attend sur le balcon de son palais, une bouteille d'eau puisée au milieu du fleuve, qu'on voit alors reparoitre dans toute sa majesté..... ${ }^{60}$.

\section{La presse francophone éditée en Russie et l'image de la Russie}

Au milieu du XVIII ${ }^{\mathrm{e}}$ siècle, la presse francophone, disséminée partout en Europe, s'étend jusqu'en Russie $^{61}$ : le premier périodique en français, le Caméléon littéraire du baron Théodore-Henri de Tschudy, est fondé à Saint-Pétersbourg en 1755 et devient, de fait, le premier journal proprement littéraire dans ce pays. D’autres vont suivre, le Journal des sciences et des arts (1761-1762), édité par Philippe Hernandez à Moscou, la Boussole de Terre (1770) de Nicolas-Gabriel Le Clerc, médecin à la cour, directeur des études au Corps des cadets nobles et futur historien de la Russie, le Mercure de Russie (1786), édité par Timoléon-Alphonse Gallien, dit Gallien de Salmorenc, ancien secrétaire de Voltaire, professeur au même Corps des cadets, le Journal littéraire de Saint-Pétersbourg (1798180o), édité par Marie Joseph Hyacinthe, chevalier de Gaston, et quelques autres, de moindre importance.

Il se forme, autour de ces périodiques, même ceux qui sont des entreprises individuelles comme le Caméléon littéraire, des cercles constitués par des correspondants étrangers et des Français expatriés en Russie. Le Mercure de Russie (1786) porte ainsi le sous-titre «Par une société de gens de lettres »: il s'agit en effet d'une société formée par des collègues et des connaissances de l'éditeur. L'étude de ces réseaux est un élément fondamental à la compréhension du phénomène de la presse francophone en Russie à cette époque. Quelles sont leurs relations avec le pouvoir autocratique et avec la grande noblesse russe ? Plusieurs évoquent en effet le soutien des autorités haut placées dont ils bénéficient: Tschudy mentionne l'appui du favori de l'impératrice, Ivan Chouvalov,

\footnotetext{
${ }^{60}$ Journal des dames et des modes, 25 janvier 1802, $\mathrm{n}^{\circ}$, p. 122-124.

${ }^{61}$ Voir sur cette question Annett Volmer, Presse und Frankophonie im 18. Jahrhundert. Studien zur französischsprachigen Presse in Thüringen, Kursachsen und Rußland, Leipzig, Leipziger Universitätsverlag, 2000.
} 
Gallien de Salmorenc fait paraître sa revue « sous les auspices de L.L.A.A.I.N.N. Alexandre et Constantin, Grands-Ducs de la Russie »...

$\mathrm{Au} \mathrm{XIX}^{\mathrm{e}}$ siècle, les liens entre certains périodiques francophones publiés en Russie et les autorités deviennent plus directs même s'ils ne sont pas toujours avoués. Le Journal du Nord est mis en place en 1807 par le ministère des Affaires étrangères avec l'objectif de contrer la propagande napoléonienne, mais il ne se déclare pas comme un organe officiel. En 1813, ce périodique est rebaptisé et devient le Conservateur impartial, il passe sous le contrôle du comte Serguëi Ouvarov, alors curateur de l'arrondissement scolaire de SaintPétersbourg, futur président de l'Académie des sciences et ministre de l'Instruction publique. Les projets d'Ouvarov sont invariablement acclamés par le Conservateur impartial. Le Bulletin du Nord paraît sous les auspices du gouverneur de Moscou, le prince Dmitri Vladimirovitch Golitsyne, lui-même parfaitement francophone et frère d'un écrivain «franco-russe », le prince Boris Golitsyne. Le Bulletin du Nord publie de la littérature russe en langue française, montrant ainsi les " progrès de la civilisation » en Russie $^{62}$.

Si des liens directs entre les périodiques francophones et les autorités russes sont plus caractéristiques de la presse du XIX ${ }^{\mathrm{e}}$ siècle que de celle du XVIII ${ }^{\mathrm{e}}$, il n'en reste pas moins qu'on peut voir des cas similaires aussi au XVIII ${ }^{\mathrm{e}}$ siècle. L'exemple du Caméléon littéraire ${ }^{63}$ montre comment cette presse, en apparence libre, pouvait s'inscrire dans le programme culturel et idéologique de la cour russe. La revue publie des articles dans différents domaines : histoire, littérature, pédagogie, mais aussi des anecdotes littéraires (par ex. sur la querelle de Voltaire et de la Beaumelle, $\mathrm{n}^{\circ}{ }_{1}$; ou sur Crébillon, $\mathrm{n}^{\circ} 2$, p. 70).

On doit à l'éditeur des "Lettres d'un vieillard à un jeune prince », publiées dans plusieurs numéros, un écrit pédagogique qui oppose deux frères dont l'un est studieux et vertueux et l'autre, paresseux et déméritant. La question de l'éducation de la jeune noblesse est aussi formulée par Tschudy dans un " Extrait du troisieme tome des ecrits satiriques imprimés en allemand a Leipzig " $\left(\mathrm{n}^{\circ} 5\right)$. Cette publication est en vérité destinée à la noblesse russe. Le journaliste y parle du choix du précepteur, des parents qui ne connaissent pas l'étendue de leurs obligations, de la délicatesse avec laquelle il faut éduquer les enfants de condition... Le thème éducatif constitue donc un des axes de ce journal ce qui n'est sans doute pas un hasard étant donné que l'éducation est justement le domaine d'activité préféré du protecteur de Tschudy, le favori Ivan Chouvalov. Chouvalov est le fondateur de l'université de Moscou qu'il présente comme une sorte de garant de la qualité de l'éducation pour la noblesse qui souffre de l'inexpérience des éducateurs, principalement étrangers, et de sa propre ignorance qui ne lui permet pas de choisir de bons professeurs. Ce programme est soutenu par Tschudy dans son journal ${ }^{64}$. Payant son tribut à l'idéologie déjà mise en place, Tschudy présente Elisabeth comme la continuatrice de l'œuvre de son père en invoquant «le nouvel Etablissement que Sa

\footnotetext{
${ }^{62}$ Voir Vladislav Rjéoutski, Natalia Speranskaia, «The Francophone Press in Russia: A Cultural Bridge and an Instrument of Propaganda », French and Russian in Imperial Russia, Derek Offord, Lara RyazanovaClarke, Vladislav Rjéoutski et Gesine Argent, vol. 1, Edimbourg : Edinburgh University Press, 2015, p. 84-102, ici p. 92-94.

${ }^{63}$ Le Caméléon littéraire. Ouvrage périodique. Par l'Auteur du Philosophe au Parnasse, Imprimé à SaintPétersbourg [à la typographie de l'Académie des sciences], 1755, (du 5 janvier au 14 décembre 1755, 49 numéros de 312 exemplaires).

${ }^{64}$ Sur cette question, je me permets de renvoyer le lecteur à mon article : Vladislav Rjéoutski, «Un journaliste français héraut de l'éducation publique en Russie : le baron Théodore-Henri de Tschudy ", Quand le français gouvernait la Russie. L'éducation de la noblesse russe, 1750-1880, textes et études réunis et présentés par Vladislav Rjéoutski, Paris : L’Harmattan, 2016, p. 233-246.
} 
Clémence vient de former pour le bien de son peuple, cette fameuse Université dont Moscou va voir décorer Sa respéctable vettusté $" 65$.

Le journaliste aborde aussi la question de l'utilité des beaux-arts et loue la politique des monarques russes qui vise la transplantation des arts occidentaux en Russie :

Bornons les arts aux besoins de la vie, aux choses nécéssaires pour la formations et le soûtien d'un état, par exemple, Agriculture, Commerce, Guerre, Architecture, Navigation etc... l'on ne peut disconvenir que le bien public n'en dépende. Il est donc juste d'acueïllir ceux qui les professent, qui sont à même de doner les vrais principes, de les faire fleurir. Le soin le plus digne d'un héros est sans doute de les récompenser. L'Auguste fondateur de ce magnifique Empire fidel imitateur d'Alexandre le Grand favorisa les arts de toute l'etendue de son pouvoir, il en conaissoit l'excellence et son gout particulier le portoit à les cultiver lui-même, son règne déstiné à être grand en tout, les vit s'elever de toute part. Notre très gracieuse Souveraine digne Héritiere des vertus eminentes anexées à son rang glorieux, continue à les protéger et leur fixe des rémunérations qu'ils ne trouveroient en aucun autre paiis ${ }^{66}$.

Faut-il rappeler que, si progressivement le regard des européens sur la Russie change, c'est en partie grâce au mythe de Pierre le Grand ? Dans la littérature française ce mythe est véhiculé et développé par Jean de Rousset ${ }^{67}$, Fontenelle ${ }^{68}$, Aubry de la Mottraye ${ }^{69}$, Mauvillon $^{70}$ et plus tard par Lacombe ${ }^{71}$ et bien entendu par Voltaire. L'Histoire de l'empire de Russie sous Pierre le Grand est le plus grand succès de la propagande russe du temps d'Ivan Chouvalov et en général l'une des actions les plus réussies de la cour russe durant tout le XVIII ${ }^{\mathrm{e}}$ siècle. La presse francophone éditée alors en Russie joue son rôle dans la diffusion d'une image positive de Pierre le Grand et de la société russe, répondant ainsi au programme formulé par le Palais (voir l'article de Vladislav Rjéoutski).

Tschudy publie aussi une "Dissertation sur l'origine et les progrès de la poesie ${ }^{72}$ qu'il dit être traduite d'un manuscrit russe ; il annonce dans le même numéro qu'on fait des

\footnotetext{
${ }^{6}$ « Réflexion sur un trait d'histoire », Le Caméléon littéraire, nº ${ }^{\circ}, 5$ Janvier 1755 . Voir également un article sur l'ouverture du pensionnat noble auprès de l'université de Moscou avec la description de la fête et de l'installation allégorique, $\mathrm{n}^{\circ} 19$.

${ }^{66}$ Le Caméléon littéraire, $\mathrm{n}^{\circ} 1,5$ janvier 1755.

${ }^{67}$ Dont les Mémoires du règne de Pierre le Grand, Empereur de Russie, sont publiés en 1725 et 1726 à La Haye en 4 vol. sous le nom d'Ivan Nestesuranoï.

${ }^{68}$ Auteur de l'Eloge du Czar Pierre I, Paris, 1727.

${ }^{69}$ Auteur des Voyages en Anglois et en François d'A. de la Mottraye en diverses Provinces et Places de la Prusse Ducale et Royale, de la Russie, de la Pologne etc. contenant un Traité de divers Ordres de Chevallerie, un grand nombre de particularités curieuses touchant le tumulte de Thorn, la Diette de Grodno, la Vie de l'Empereur de Russie Pierre I, celles de l'Impératrice Catherine, du Général Lefort et du prince Menzikoff: Avec des Remarques géographiques, topographiques, historiques et politiques sur ces Provinces et autres Païs par lesquels l'auteur a passé et repassé : comme le Mecklembourg, la Poméranie, la Courlande, la Livonie, l'Estonie, les Principautés de Preskoff et de Novgorod, le lac Ladoga, la Carélie, l'Ingrie, la Silésie, le Brandebourg et sur quelques parties de la France, de la Flandre, de l'Angleterre et de l'Irlande. Tirées nonseulement de ses observations, mais encore des Mémoires qui lui ont été communiqués par des personnes de considération et dignes de foi, enrichies de plans et de figures, La Haye : imprimé pour l'Auteur et se vend chez A. Mœtjens etc., 1732.

$7^{70}$ Auteur de l'Histoire de Pierre I, surnommé le Grand, Empereur de toutes les Russies..., Amsterdam : Leipzig, 1742.

${ }^{71}$ Auteur de l'Histoire des révolutions de l'empire de Russie, Amsterdam, 176o et Paris, 176o.

${ }^{72}$ « Dissertation sur l'origine et les progrès de la poésie, fondée sur le témoignage des anciens auteurs grecs et latins, auquels on a joint celui des auteurs modernes », Le Caméléon littéraire, $\mathrm{n}^{\circ} 11$ du 16 mars $1755 ; \mathrm{n}^{\circ} 15$ du 13 avril 1755. Tschudy serait en effet le traducteur et non pas l'auteur de ce texte car on retrouve le même
} 
vers en Russie ! Il réfléchit sur les possibilités de chaque nation de parvenir aux sciences : « Nos yeux, la raison, l'expérience, sont des avantages communs à toutes les nations ». N'importe quelle nation pourrait arriver au même stade de développement que les pays les plus civilisés de l'Europe et la nation russe n'en fait pas exception, le tout est d'avoir le temps nécessaire ; les Russes donnent déjà des preuves incontestables des progrès de leur civilisation.

Il est évidemment difficile de dire si les publications favorables à la Russie et à ses souverains sont commandées par les protecteurs russes de ces journalistes ou si les journalistes prennent eux-mêmes l'initiative, sans doute les deux. Dans certains cas, on peut détecter des interactions et des frictions au sujet de questions précises comme dans le cas de Voltaire: il est constamment encensé par Tschudy ce qui suscite le mécontentement de ses protecteurs car Voltaire n'est pas bien vu à la cour de Russie en 1755 (voir l'article de Vladislav Rjéoutski).

Des publications avec des visées propagandistes continueront de paraître dans la presse francophone publiée en Russie. En 1786, le Mercure de Russie ${ }^{73}$ annonce son intention de

faire voir combien l'Education a fait de progrès en Russie depuis une trantaine [sic !] d'Années et quels avantages elle a sur celle de plusieurs peuples très éclairés d'ailleurs, mais qui n'ont pu, ou n'ont pas osé en bannir d'anciennes méthodes, qui s'opposeront toujours chez eux aux progrès de l'Esprit humain ${ }^{74}$.

Dans le même numéro, l'éditeur loue la tolérance religieuse qui règne en Russie. Il relate l'organisation par Catherine II d'un dîner où l'impératrice réunit les représentants de toutes les confessions de l'empire :

Ce Repas, si honorable pour l'humanité, où présidait la Tolérance universelle, passerait peut-être pour incroyable, dans quelques Pays Méridionaux de l'Europe, si tout le Nord n'en avait été témoin. Il était réservé à Catherine d'opérer un tel miracle, et de forcer des Communions, si divisées, jusqu'alors, à se réunir, pour bénir le Règne le plus juste, le plus éclairé, le plus humain et le plus glorieux qui fût jamais, remarque-t-il ${ }^{75}$.

Gallien de Salmorenc fait également des efforts pour promouvoir la littérature russe dans les pages de son journal, ce que quelques trente ans plus tôt Tschudy avait beaucoup de mal à faire, ne connaissant quasiment aucun exemple de travaux littéraires russes, exceptés peut-être ceux de Lomonossov et de Soumarokov.

Avant le Régne de Pierre le Grand, qui débrouilla tout, rien, eu égard aux Belles Lettres, n'étoit digne de beaucoup d'attention [en Russie]. [...] La Nation Russe, doüée des plus étonnantes dispositions, ayant reçû si tard la Lumière, qui brilloit depuis peu, ait marché,

contenu dans une dissertation intitulée «О качествах стихотворца рассуждение» [«Dissertation sur les qualités du poète»] publiée en russe deux mois plus tard dans la revue Ежемесячные сочинения. Се dernier texte devrait être attribué à Grigori Nikolaevitch Teplov, voir G. Achinger, Der französische Anteil an der russischen Literaturkritik des 18. Jahrhunderts unter besonderer Berücksichtigung der Zeitschriften (1730-1780), Bad Homburg, Berlin, Zurich, 1970, p. 83-104, indication dans Annett Volmer, Presse und Frankophonie, op.cit., 2000, p. 194.

73 Sur le Mercure de Russie, voir notamment Д. Кобеко, «Французский журнал в С.-Петербурге», Российская библиография [D. Kobeko, «Un journal français à Saint-Pétersbourg », Rossiiskaïa bibliografiia], n¹01, 1882, p. 3-6.

${ }^{74}$ Le Mercure de Russie, 1786, janvier et février, p. 108.

${ }^{75}$ Ibid., p. 131-135, ici p. 131-132. 
à pas de Géans, pour Franchir si vite l'intervalle immense qui la séparoit des nations policées, long tems avant elle ${ }^{76}$.

Le journaliste publie en traduction française plusieurs œuvres de Théophane Prokopovitch, l'un des partisans les plus actifs de Pierre le Grand et littérateur de talent. Toutes ces publications portant sur la littérature paraissent dans la rubrique « Histoire littéraire de Russie ", ce qui est en soi une sorte de proclamation. Le journaliste fait aussi l'annonce de pièces de théâtre publiées en russe, notamment de l'Imposteur, une comédie de Catherine II parue peu de temps avant sous un anonymat qui était facilement perçu par le public ${ }^{77}$. Gallien de Salmorenc analyse dans le même numéro la traduction française de cette pièce ${ }^{78}$ ce qui ajoute un élément supplémentaire à la présentation qu'il fait : non seulement les Russes produisent des œuvres littéraires dignes de l'attention d'un public cultivé, mais ces œuvres sont aussi traduites dans la «langue de l'Europe » pour le plaisir des amateurs européens de la littérature ne maîtrisant pas le russe. Cet usage de la littérature russe n'est pas sans rappeler ce que font aussi certains journaux français à la même époque (voir l'article de Carole Chapin). La vie scientifique russe n'est pas oubliée : le journal annonce les concours proposés par l'Académie des sciences de SaintPétersbourg, à côté des concours d'autres académies européennes (Académie Française, la Société Royale des Sciences de Göttingen, la Société Royale de Londres...) ${ }^{79}$, ce qui crée l'impression d'un espace culturel continu, sans frontières, dans lequel la Russie occupe désormais une place de choix. Le journal enchaîne avec le "Progrès des Arts, des Sciences, et des Belles Lettres en Russie, sous le Règne de Catherine II ", où on peut lire les vers suivants :

Tu sçais te partager entre Minerve et Mars; et, ce qu'avec raison, toute l'Europe admire, tout Art est citoien dans ton heureux Empire.

Le Russe excelle en tout, et son essor étonne ${ }^{80}$

On trouve d'autres exemples de ce genre de flagorneries un peu plates dans le même journal, par exemple une ode " Le Siècle de Catherine II » (allusion transparente au Siècle de Louis XIV de Voltaire) dans laquelle sont encensés, à tour de rôle, les efforts de Catherine législatrice, sa politique étrangère, notamment sa croisade contre les infidèles, etc. :

En effet son heureux Empire.

Est le plus ferme appui des Loix:

Sur son Front la douceur respire,

L'Equité parle par sa voix.

De ses sujèts Mère propice,

Hérö̈ne, Législatrice:

Voilà ses titres glorieux.

Toujours Grandes, et toujours sublime,

\footnotetext{
${ }^{76}$ Ibid., mars et avril, p. 5-7.

77 Ibid., p. 21-23.

${ }^{78}$ Ibid., p. 29 etc. Le journal consacre aussi un article à l'analyse de la première de la même pièce à SaintPétersbourg, p. 51-68.

${ }^{79}$ Ibid., p. 43-44.

${ }^{80}$ Par M. Clarmonse, ibid., p. 110-113.
} 
Son but, son unique Maxime

Est que ses Peuples soient heureux.

Et l'auteur poursuit :

Et toi Pologne Infortunée, mais heureuse dans ton malheur, par ses soins la paix t'est donnée: par ses soins renait ton bonheur.

En proye aux plus vives allarmes, L'Europe vit l'humble Sultan, à ses pieds mettre bas les armes, l'Aigle terrasser le Croissant.

Des Loix l'Auguste Sanctuaire aux Russes enfin est ouvert; un Code utile et nécessaire Par sa main vient d'être offert ${ }^{81}$.

A la fin du siècle, le Journal Littéraire de Saint-Pétersbourg, est également soutenu par les autorités, et pour cause : l'image de l'Empire de Russie qu'il renvoie est bien celle d'un pays où fleurissent la littérature, le théâtre, les beaux-arts (voir l'article de Vladimir Somov).

\section{Les réseaux d'influence}

Si une partie de la presse francophone des Lumières propose à ses lecteurs une image positive de la Russie, c'est dû non seulement à la curiosité pour ce pays neuf en pleine mutation, mais également aux liens étroits établis entre ces périodiques et la Russie.

Les liens savants, dès l'apparition de l'Académie des sciences à Saint-Pétersbourg, sont constants, intenses et diversifiés. Daniel Ernst Jablonski, prédicateur à la cour prussienne, longtemps secrétaire et vice-président de la Société des sciences de Brandebourg et, de 1733 à 1741, président de l'Académie des sciences de Berlin, proche du journal, et Jean Henri Samuel Formey, secrétaire perpétuel de l'Académie berlinoise et directeur du journal, entretiennent des correspondances avec des savants pétersbourgeois et des agents littéraires russes. Du côté russe, Heinrich von Huyssen, déjà mentionné, Johann Daniel Schumacher et Leonhard Euler sont particulièrement actifs. Huyssen, membre honoraire de la Société des sciences de Berlin, correspond avec Daniel Ernst Jablonski, et leur échange est relativement intense ${ }^{82}$. Schumacher, le bibliothécaire de l'Académie, parcourt en 1721 plusieurs pays européens à la demande de Pierre $\mathrm{I}^{\mathrm{er}}$, afin notamment d'engager des savants pour l'Académie pétersbourgeoise et d'établir des correspondances. Il indique parmi ses interlocuteurs de La Croze et Jablonski ${ }^{83}$. Plusieurs des académiciens de Saint-Pétersbourg sont en contact direct avec les éditeurs de la Bibliothèque germanique: Gottlieb Siegfried Bayer, Daniel Bernouilli, Joseph-Nicolas Delisle, Georg Bernhard Bilfinger, Christian Holdbach. Il y a même des connexions directes entre certains membres de la Société Anonyme, société de gens de lettres qui a fondé la

\footnotetext{
${ }^{81}$ Ibid., juillet, p. 113-120, par Gallien de Salmorenc.

${ }^{82}$ Archives de l'Académie des sciences de Russie, filiale de Saint-Pétersbourg (SPFA RAN), fonds 119, D1, $\mathrm{n}^{\circ} 4$.

${ }^{83}$ Voitenko, La Présentation de la Russie dans la presse francophone, op. cit., p. 34-35.
} 
Bibliothèque Germanique, et la Russie, à travers leurs familles: Louis L'Enfant, fils de Jacques L'Enfant, un des directeurs du journal, a été prédicateur d'une paroisse protestante à Moscou entre 1698 et 1701 ; Léopold de Beausobre, fils d'Isaac de Beausobre, un autre directeur du même journal, a été militaire au service de la Russie à partir de 1720, y a été promu au grade de général-major et y a fait souche ${ }^{84}$. Sous ce rapport, le cas de la Bibliothèque Germanique, peut-être à part, n'est cependant pas unique. On peut mentionner Jean Rousset de Missy ${ }^{85}$, membre honoraire de l'Académie des sciences pétersbourgeoise, journaliste en vue à cette époque, collaborant au Mercure historique et politique et à la Bibliothèque Raisonnée, qui est en contact avec l'Académie de Pétersbourg et notamment avec son bibliothécaire, Schumacher, et cherche des auteurs pour écrire des comptes rendus d'ouvrages publiés par l'Académie pétersbourgeoise ou en insère luimême, par exemple dans la Bibliothèque raisonnée ${ }^{86}$. Les affaires académiques russes restent, dans la deuxième moitié du XVIII ${ }^{\mathrm{e}}$ siècle, un des points d'attraction pour les journalistes européens et contribuent, comme auparavant, à redorer l'image de la société russe. Sous Catherine II, une correspondance régulière est entretenue entre Johann Albrecht Euler et son oncle Samuel Formey qui sert de relais aux informations académiques de Saint-Pétersbourg. On ne s'étonne donc guère de trouver une pléthore de publications sur l'Académie impériale dans certains périodiques francophones publiés dans les pays allemands, comme la Gazette universelle de littérature, aux Deux-Ponts ${ }^{87}$.

Pourtant, au milieu du siècle, l'influence russe dans les publications périodiques occidentales semble diminuer par rapport à l'époque précédente, celle des agents littéraires pétroviens comme Huyssen et des relations intenses entre l'Académie de SaintPétersbourg et les journaux savants. En revanche, Ivan Chouvalov utilise la presse francophone russe se trouvant sous son contrôle et diversifie les moyens de propagande qui incluent la publication de discours célébrant les progrès de la Russie sur la voie de la civilisation (discours de l'abbé Faure, 1760 , prononcé à Saint-Pétersbourg même ${ }^{88}$ ), et la commande d'œuvres littéraires et polémiques à divers auteurs francophones (le baron de Tschudy, le chevalier de Mainvilliers, auteur d'un poème épique, La Pétréade, le chevalier Dezessart, auteur du Voyageur moscovite et, dernier exemple et non des moindres, Voltaire).

\footnotetext{
${ }^{84}$ Les Français en Russie au siècle des Lumières, sous la dir. d'Anne Mézin et de Vladislav Rjéoutski, FerneyVoltaire : CIEDS, 2011, vol. 2, p. 58-59, 514.

${ }^{85}$ Voir sur lui : Le métier de journaliste au dix-huitième siècle : correspondance entre Prosper Marchand, Jean Rousset de Missy et Lambert Ignace Douxfils, sous la dir. de Christiane Berckvens-Steverlynck et Jeroom Vercruysse, Oxford : Voltaire Foundation, 1993 ; Г.А. Шатохина, « Голландский публицист Жан Руссе де Мисси и его связи с Россией » [G.A. Chatokhina, « Le journaliste hollandais Jean Rousset de Missy et ses relations avec la Russie »], Russia and the Low Coutries in the Eighteenth Century / Россия и Нидерланды в XVIII веке, ed. Emmanuel Waegemans, Groningen, 1998, p. 111-123; С.А. Мезин, «Голландский публицист Жан Руссе де Мисси как биограф Петра I», Россия - Нидерланды. Диалог культур в европейском пространстве. Материалы V Международного петровского конгресса [« Le journaliste hollandais Jean Rousset de Missy comme biographe de Pierre $\mathrm{I}^{\mathrm{er}}$ ", Russie - Pays Bas. Dialogue des cultures dans l'espace européen. Actes du $V^{e}$ Congrès international Pierre le Grand], Saint-Pétersbourg, 2014, p. 442457.

${ }^{86}$ Voitenko, La Présentation de la Russie dans la presse francophone, op. cit., p. 34, 39.

${ }^{87}$ Dulac, « L'image de la Russie dans les gazettes », art. cit., p. 86.

88 Sur cette question, voir par exemple К. Осповат, «Государственная словесность: Ломоносов, Сумароков и литературная политика И.И. Шувалова в конце 1750-х гг.», Европа в России: сборник статей [Kirill Ospovat, «Les belles-lettres d'Etat: Lomonossov, Soumarokov et la politique littéraire d'Ivan Chouvalov à la fin des années 1750 ", L'Europe en Russie: recueil d'articles], Moscou : Novoïé litératournoïe obozrénié, 2010, p. 6-65, ici p. 12-13.
} 
On peut penser que la décision de s'adresser à Voltaire s'explique, du moins en partie, par la compréhension du fait que les écrivains francophones de l'entourage de Chouvalov, étant peu connus dans la république des Lettres, ne sont pas capables de porter la parole de Saint-Pétersbourg partout en Europe et que le seul journal francophone de SaintPétersbourg, même s'il est agréable à Chouvalov, ne permet pas d'atteindre le lectorat qui se trouve en dehors de la Russie. L'apparition, en 1760, sur les pages de l'Année littéraire de l'abbé Fréron, d'un article (écrit probablement par un parent proche d'Ivan Chouvalov, Andreï Petrovitch Chouvalov, ou par Alexandre Stroganov) qui traite des progrès de la littérature russe et parle des deux littérateurs russes les plus en vue, Lomonossov et Soumarokov, s'inscrit parfaitement dans cette stratégie. En même temps, cet article est d'abord et surtout le fait des nouveaux réseaux qui se tissent entre Saint-Pétersbourg et Paris à partir de l'intensification des contacts entre les deux pays : en 1756, la France et l'Autriche concluent une Alliance, la France cherche le soutien de la Russie. Le chevalier d'Eon de Beaumont, qui accompagne le chevalier Douglas à Saint-Pétersbourg en 1757 comme son secrétaire, est un des collaborateurs de Fréron. D'Eon approche plusieurs aristocrates russes, il mentionne dans sa correspondance le comte Mikhaïl Vorontsov, vice-chancelier de l'Empire, sa nièce Catherine, future princesse Dachkova, le chambellan Ivan Chouvalov, favori de l'impératrice Elisabeth, etc. Le chevalier Douglas leur fait envoyer de Paris une correspondance littéraire pour divertir cette cour qui s'ennuie, affirme d'Eon. C'est sans aucun doute par ce dernier que Fréron reçoit de nombreux textes sur la Russie comme le montre Alexandre Stroev. Ces publications permettent à Fréron, loyal au gouvernement français, de caresser l'amour-propre des Russes au moment où la France engage la Russie à s'allier à elle, mais aussi de concurrencer son ennemi, le Journal encyclopédique proche des philosophes, qui s'intéresse aussi à la Russie $^{89}$.

Catherine II va enchaîner avec cette politique qui privilégie les relations avec les faiseurs d'opinion dans le monde intellectuel occidental, comme Voltaire et Diderot, et des actions de propagande spectaculaires, comme l'achat de la bibliothèque de Diderot, la traduction de son Instruction à la Commission des lois ou Nakaz, celle des statuts de ses établissements éducatifs ou encore celle du Bélisaire de Marmontel ${ }^{90}$. Mais la presse n'est jamais très loin et son rôle dans les actions de "propagande » de Catherine II est aussi considérable. Les nouvelles de Russie sont quelquefois acheminées par les correspondants occidentaux de Catherine, voire par des réseaux plus complexes.

C'est ainsi que les nouvelles de la "révolution » opérée par Catherine, qui détrône son mari, parviennent en 1762 au Journal encyclopédique vraisemblablement par l'intermédiaire de François-Pierre Pictet, qui se rapproche de Catherine, et qui sert de chaînon entre elle et Voltaire. C'est probablement ce dernier qui les envoie aux journalistes. Elles se répandent dans la presse, notamment dans la Gazette d'Utrecht ${ }^{91}$. Dès les premiers jours de son règne Catherine est proclamée le modèle des rois : « [...] le

\footnotetext{
${ }^{89}$ А.Ф. Строев, «Защита и прославление России: история сотрудничества шевалье д’Эона и аббата Фрерона» [Alexandre Stroev, «La défense et l'illustration de la Russie : l'histoire de la coopération entre le chevalier d'Eon et l'abbé Fréron»], Les Français dans la vie intellectuelle et scientifique en Russie (XVIII ${ }^{e}$ $X X^{e}$ ), sous la dir. de A.O. Tchoubarian et de F.-D. Liechtenhan, Moscou : Olma Media Group, 2010, p. 164174 .

90 Voir à ce sujet le livre d'Albert Lortholary, Le mirage russe au XVIII siècle, Paris, Editions contemporaines, Boivin, 1951, et la révision critique de ce travail, Le Mirage russe au XVIII siècle, textes publiés par Sergueï Karp et Larry Wolff, Ferney-Voltaire : CIEDS, 2001, ainsi que les travaux de Georges Dulac et de Sergueï Karp sur Diderot.

${ }^{91}$ Voir à ce sujet Nicholas Hans, «François Pierre Pictet, Secretary to Catherine II », The Slavonic and East European Review, 1958, vol. XXXVI, n 87, juin, p. 481-491.
} 
trône de Russie est occupé aujourd'hui par une Souveraine qui doit être le modèle des Rois $[\ldots]^{92} »$.

L'histoire de la " couverture médiatique » de l'achat de la bibliothèque de Diderot en 1765, démêlée par Roland Desné, montre quels réseaux relaient les informations sur les actions de la nouvelle impératrice russe ${ }^{93}$. La proposition faite par Grimm à la cour de Russie, sur le conseil de l'ambassadeur de Russie en France, d'acheter la bibliothèque de Diderot, qui se trouve alors dans une situation financière compliquée, reçoit en mars un accueil favorable par la voie d'Ivan Betskoï, proche collaborateur de Catherine. Déjà le 15 avril, cette lettre de Betskoï est reproduite dans la Correspondance littéraire de Grimm, à la suite de laquelle la nouvelle est annoncée dans les Nouvelles à la main de Bauchaumont le 20 avril ; fin avril le Journal des dames et le Courrier d'Avignon en parlent ; dans ce dernier, la nouvelle est précédée de cet éloge : "L'impératrice de Russie entretient et cultive dans ses Etats le goût de la littérature que Pierre le Grand y a introduit avec tous les autres goûts des nations polies ${ }^{94}$. Voltaire, J.-J. Rousseau, d'Alembert, Dorat apprennent la nouvelle très vite et ne tarissent pas d'éloges à l'égard de Catherine II. Ainsi, D'Holbach écrit à Servan : "Par ce procédé aussi délicat que généreux, vous voyez qu'en Tartarie, on pense plus noblement qu'en France ${ }^{95}$. Dorat écrit une épître à Catherine II, probablement sur l'idée de $\mathrm{Grimm}^{96}$, et cette épître est publiée par la Correspondance littéraire et reproduite par l'Année littéraire, puis commentée et partiellement reproduite dans l'Avant-coureur, fin juillet, et dans le Journal des Dames, en août. Une autre épître faisant écho à cet événement, celle de Légier à M. Diderot, qui elle aussi vante les mérites de Catherine II, paraît en mai dans la Correspondance littéraire de Grimm, est partiellement reproduite par le Mercure en juillet, sort en édition séparée qui est recensée dans le Journal des dames en août, est de nouveau reproduite en août par la Gazette littéraire de l'Europe, qui paraît à Amsterdam, recensée dans l'Avant-coureur en septembre, etc. Bachaumont se répand en éloges à Catherine II : "Cette moderne Sémiramis ne borne pas ses vues à la plus sage administration [...] elle s'occupe encore journellement de ce qui peut la rendre célèbre et chère aux gens de lettres ; étend chez les puissances étrangères cette main bienfaisante qui la fait adorer aujourd'hui $»{ }^{97}$. Comme le remarque Roland Desné, un événement de la vie privée a ainsi été transformé en un événement national et européen ${ }^{98}$. On a l'impression que ces nouvelles se répandent d'elles-mêmes dans les réseaux intellectuels et journalistiques des Lumières, ce qui est en partie vrai car l'événement est un acte de mécénat hors du commun qui étonne et cause de l'admiration, mais n'oublions pas le rôle central de Grimm et de sa Correspondance littéraire dans ce coup médiatique. Durant de longues années, Voltaire, Grimm, Diderot, La Harpe, Thomas et Marmontel entretiennent, chacun à sa manière, l'intérêt du public européen pour la Russie en formant, avec les diplomates russes, selon le mot de Georges Dulac, un « service de presse » efficace ${ }^{99}$.

\footnotetext{
$9^{2}$ Journal encyclopédique, 1762 , t. $7,3^{\mathrm{e}}$ partie, novembre, p. 130. Je remercie Nadejda Dorokhova.

93 Roland Desné, "Quand Catherine II achetait la bibliothèque de Diderot », Thèmes et figures du siècle des Lumières. Mélanges offerts à Roland Mortier, éd. par Raymond Trousson, Genève, Droz, 1980, p. 73-106.

${ }^{94}$ Le Courrier d'Avignon, nXXXV, p. 142. Cité d'après Desné, « Quand Catherine II achetait la bibliothèque de Diderot », art. cit., p. 76 .

${ }^{95}$ Cité d'après Desné, « Quand Catherine II achetait la bibliothèque de Diderot », art. cit., p. 75.

${ }^{96}$ Desné, « Quand Catherine II achetait la bibliothèque de Diderot », art. cit., p. 84.

${ }^{97}$ Cité d'après Desné, « Quand Catherine II achetait la bibliothèque de Diderot », art. cit., p. 76-77.

${ }^{98}$ Roland Desné, « Quand Catherine II achetait la bibliothèque de Diderot », art. cit., p. 93.

${ }^{99}$ Dulac, « L'image de la Russie dans les gazettes », art. cit., p. 86.
} 
Les succès de Catherine II, qui assurent à la Russie une place de choix dans les affaires européennes, ne sont guère du goût des diplomates français, mais les bruits malveillants que certains périodiques proches de Versailles répandent sur les affaires russes ne sont pas seulement l'effet de l'influence française sur la presse francophone européenne, mais également la suite des difficultés que les journalistes comme les diplomates en poste en Russie rencontrent pour obtenir des informations fiables sur ce pays : l'éloignement et la mauvaise connaissance de la Russie, la désinformation ou la rétention systématique des nouvelles pratiquées par les autorités russes et souvent invoquées par les diplomates (Diderot en fait l'expérience lors de son séjour à Saint-Pétersbourg) ${ }^{100}$. Dans cette situation, plusieurs moyens sont utilisés pour obtenir des renseignements sur la Russie : des pots de vin qui permettent au diplomate français Durand de Distroff d'envoyer à ses supérieurs des informations diverses sur l'empire de Catherine II, informations qui servent aussi à alimenter les gazettes proches de Versailles ; des expatriés français qui lui fournissent des informations (Nicolas-Gabriel Clerc, futur Le Clerc, médecin du grandduc héritier, directeur des études au Corps des cadets et proche de l'influent Ivan Betskoï ; Vivant Denon qui est un intime des Bibikov, mère et fille, qui le renseignent sur les actions militaires du général contre Pougatchev), etc. La multiplication des sources d'informations (différentes gazettes européennes, mais également la Gazette de SaintPétersbourg qui est à cette époque publiée en russe et en allemand et dont les renseignements sont analysés jusqu'à en montrer des invraisemblances ${ }^{101}$ ) assurent aux journalistes des informations sinon toujours fiables, du moins abondantes ${ }^{102}$.

A la fin du siècle, les émigrés qui fondent quelques périodiques francophones dans les Etats allemands entretiennent des relations suivies avec la Russie. Le marquis Henri Joseph de Lambert, agent de Catherine II, réfléchit à la possibilité de créer un journal d'émigrés à Brunswick et propose Jacques Mallet du Pan et Jean Joseph Mounier pour remplir la fonction d'éditeurs de ce journal. Quand le duc Charles-Guillaume-Ferdinand de Brunswick-Wolfenbüttel oppose son refus à l'idée de faire paraître le périodique des émigrés à Brunswick, il craint évidemment la réaction de la France républicaine, d'où la proposition d'une ville libre comme Hambourg, moins sujette au contrôle tatillon des Français... Le Spectateur du Nord est enfin fondé dans cette dernière ville même s'il continue d'être soutenu et longtemps imprimé à Brunswick. Les personnes qui se trouvent à son origine (le marquis de la Maisonfort, Baudus, Fauche) sont toutes liées à quelques personnalités officielles russes, d'abord et surtout au ministre russe à Hambourg, Ivan Mouraviev-Apostol. Le même Mouraviev-Apostol intervient quand le Sénat de Hambourg interdit un autre journal d'émigrés, Le Censeur, et emprisonne son éditeur Bertin d'Antilly, libéré grâce au soutien des Russes. Il n'est pas étonnant de voir que certaines des plumes qui remplissent ces périodiques émigrés vont plus tard être accueillies en Russie, comme les marquis de La Maisonfort et de Mesmon. Ce dernier, tiré lui aussi des prisons de Hambourg par ses protecteurs russes, devient en Russie conseiller d'Etat et commandeur de l'ordre de Sainte-Anne, est employé au ministère de l'Instruction publique et occupe la fonction de rédacteur du Journal du Nord, périodique officieux du ministère des Affaires étrangères édité à Saint-Pétersbourg (voir l'article de Vladimir Somov dans ce numéro).

\footnotetext{
${ }^{100}$ Dulac, « L'image de la Russie dans les gazettes », art. cit., p. 78.

${ }^{101}$ Comme le fait le Journal historique et littéraire en parlant de Pougatchev.

${ }^{102}$ Dulac, « L'image de la Russie dans les gazettes », art. cit., p. 80-81.
} 
La presse francophone européenne, s'appuyant sur la popularité du français en Europe, est un des outils privilégiés de propagande au XVIII ${ }^{\mathrm{e}}$ siècle. Toutes les grandes puissances l'utilisent à cette fin : la Prusse, la France, l'Autriche ; et la Russie ne fait pas exception. En même temps, il ne faut pas oublier que c'est un outil parmi d'autres, mais probablement l'outil propagandiste le plus important et dont les effets sont loin d'être appréciés à leur juste échelle.

L'usage de la presse à des fins de propagande passe par un travail souvent de longue haleine comme on le voit sur l'exemple de quelqu'un comme Heinrich von Huyssen. Les liens noués entre les représentants de la Russie et la presse européenne expliquent la régularité avec laquelle des informations «russes» apparaissent sur les pages de ces périodiques et, dans une certaine mesure, le regard favorable jeté par eux sur les affaires russes.

Pour autant, toutes les personnes qui approchent les journalistes ne sont pas des agents littéraires ou des diplomates russes : les savants le font afin de promouvoir leurs recherches auprès de leurs collègues européens et les littérateurs, afin d'être reconnus en dehors de leur lectorat immédiat et de se sentir acceptés dans la république des lettres européenne. Mais même en cas de démarches à première vue purement personnelles, la gloire de la Russie, de cette Russie européenne que Pierre a " arrachée au néant », est un des motifs forts pour les Russes qui s'identifient avec leur pays. Plusieurs agents littéraires nouant des contacts avec des journalistes sont des étrangers au service de la Russie qui font figure de projecteurs. S’ils suivent certaines lignes directrices, ils ont souvent une certaine liberté quant aux moyens pour atteindre leurs objectifs. Mais les rappels à l'ordre adressés au baron de Tschudy montrent que cette liberté est relative, particulièrement quand il s'agit de journalistes travaillant dans la Russie même.

Les représentations de la Russie et de ses souverains que les diplomates et les agents littéraires russes proposent aux médias ou que ceux-ci renvoient traduisent leur idée de la " civilisation" russe : à côté des succès des armes russes, ils mettent en évidence le progrès des sciences, des arts, de la littérature, de l'éducation et de la sociabilité, les beautés de la capitale de Pierre et l'éclat de sa cour... Le travail est difficile car d'autres périodiques, subissant d'autres influences ou suivant les vieux clichés, présentent une image différente, celle d'une société barbare et arriérée.

Les conséquences de la "propagande » russe sont encore difficiles à saisir dans toute leur ampleur et leur complexité. Habitués à voir dans ce genre d'actions un certain cynisme, nous risquons de passer à côté de leurs effets positifs. Renvoyant aux occidentaux et aux Russes eux-mêmes (car certains des périodiques occidentaux sont lus par les élites russes, d'autres sont publiés dans la Russie même) une image idéalisée de ce pays, cette presse contribue à sa façon à l'européanisation de la Russie à différents niveaux, facilitant le dialogue interculturel et créant des conditions pour l'introduction en Russie d'idées et de pratiques occidentales qui transforment progressivement la société russe. 